\title{
Pregnancy outcomes in the extremes of reproductive age: A seven-year experience in Tanzania
}

\author{
Projestine S. Muganyizi, Belinda Balandya \\ Department of Obstetrics \& Gynecology, Muhimbili University of Health and Allied Sciences (MUHAS), Dar es Salaam, Tanzania \\ Email: promuga@yahoo.com, $\underline{\text { lindabsoft@gmail.com }}$
}

Received 23 November 2012; revised 26 December 2012; accepted 5 January 2013

\begin{abstract}
Background: Extremes of reproductive age are associated with adverse pregnancy outcomes. Although varieties of adverse outcomes are reported across international studies, it has been difficult to compare the results due to inconsistencies in design partly due to arbitrary age cut offs for low and high risk groups. This study utilized the international consensus age cut offs to separate low and high risk age groups and compared pregnancy outcomes among them. Methods: Data of all deliveries at the Muhimbili National Hospital in Dar es Salaam, Tanzania from $1^{\text {st }}$ January, 2005 to $31^{\text {st }}$ December, 2011 were analyzed retrospectively and compared using IBM SPSS statistics 19. Ages 12 - 17 years (teenage) and 35 - 50 years were classified as high risk and 18 - 34 years as low risk. We treated the presence of any prenatal complication as primary outcome and intra/postpartum variables as secondary outcomes. Chi square test was used to compare proportions and t-test for continuous data among two independent groups. ANOVA with Bonferroni adjustment was used to compare differences in means across age groups. Binary logistic regression analyses were performed to determine odds of developing primary and secondary outcomes with age as an independent (categorical) variable. P-values of 0.05 or less were interpreted as statistically significant. Results: In total $\mathbf{6 5 , 4 5 3}$ singleton deliveries were identified of which $64,818(99 \%)$ were analyzed including $1680(2.6 \%)$ teenage and 7961 (12.3\%) deliveries at 35 - 50 years. Teenage deliveries had progressively declined from $39 / 1000$ in 2005 to $16 / 1000$ in 2011 in contrast to a rise from $103 / 1000$ to $145 / 1000$ deliveries for the 35 - 50 years. Across all age groups, prenatal complications were least for teenage $(\mathbf{1 1 . 4 \% )}$ and most for 35 - 50 years $\left(32.7 \%, \chi^{2}=51.3, P<\right.$ $0.0001)$. With reference to age 18 - 34 years, teenage deliveries had significantly lower odds for prenatal complications (OR $=0.4,95 \%$ CI: $0.3-0.5)$, and for delivery of $4.0 \mathrm{~kg}$ or more $(\mathrm{OR}=0.3,95 \% \mathrm{CI}: 0.2$ 0.5). Further, teenage deliveries had comparable odds
\end{abstract}

for Cesarean section, stillbirths and maternal deaths. However, they had less antenatal care attendance $(\mathrm{OR}=0.3,95 \%$ CI: 0.3 - 0.4), more low APGAR score deliveries at five minutes $(\mathrm{OR}=\mathbf{2 . 2}, 95 \% \mathrm{CI}: 1.9$ - 2.6) and low birth weight $(O R=1.6,95 \% \mathrm{CI}: 1.4$ - 1.8). In contrast, deliveries at 35 - 50 years had increased risks for Cesarean section $(\mathrm{OR}=1.4,95 \% \mathrm{CI}$ : 1.3 1.5), low birth weight $(\mathrm{OR}=1.2,95 \% \mathrm{CI}: 1.1-1.3)$, babies weighing $4.0 \mathrm{~kg}$ or more $(\mathrm{OR}=1.2,95 \% \mathrm{CI}$ : $1.08-1.2)$ and maternal death $(O R=1.4,95 \%$ CI: 1.1 - 2.0). The risks for prenatal complications and stillbirths were also increased for the 35 - 50 years but not after adjusting for confounders. Conclusion: Deliveries at 35 years or above were on increase and were associated with the worst pregnancy outcomes at MNH.

Keywords: Maternal Age; Pregnancy Outcome; Trends; Prenatal; Postnatal; Tanzania

\section{INTRODUCTION}

Extremes of maternal age are known to be associated with poor maternal and perinatal outcomes. Many studies have addressed pregnancy outcomes in the extremes of reproductive age, but the comparison of results is often hindered by inconsistencies both in study designs and interpretation of results. A frequent reason given for adverse pregnancy outcomes of women in the lower extreme of reproductive age has been the women's socioeconomical disadvantages [1,2] but this reasoning is not supported by others $[3,4]$. For older women, poor obstetric outcomes are frequently attributed to increased risk of genetic and medical disorders. Although many studies have reported increased risk for adverse pregnancy outcomes with both extremes of maternal age [5-8], some hold that the risk is not alarming particularly when pre-existing medical disorders or previous reproductive problems were controlled $[9,10]$.

The inconsistent assignment of certain maternal age groups into low and high risk is a commonly observed 
design problem. Some studies treat the age below 20 years as generally risky for obstetric complications $[4$, 6-8,11-13] while others hold that older teenagers (17 - 18 years) have comparable outcomes to low risk controls $[2,14,15]$. The arbitrary assignment of heterogeneous age groups as risky or as controls may seriously interfere with the interpretation of results. For the upper extreme of maternal age, the design of some studies seem to agree with the age 35 years or above as explicitly high risk [5-7,16-19] while others have done so indirectly by avoiding this age group as a control in their comparisons $[10$, 20].

In order to alleviate the cut off age controversy, UNICEF, UNFPA and WHO based on current evidence, have recommended delay of the first pregnancy until the age of 18 years [21,22]. Implicitly this 18 years age becomes an international consensus cut off age for low and high risk maternal ages in the lower reproductive age extreme. Since a consensus among international researchers also support the 35 years age as a cut off for low and high risk maternal ages in the upper extreme of reproductive age, we decided to use this and the 18 years ages as our cut offs for high and low risk age groups respectively for the current study. The study aimed to establish annual trends and pregnancy outcomes of high risk age groups and compare pregnancy outcomes among them. We studied delivery records of all deliveries that took place at $\mathrm{Mu}-$ himbili National Hospital (MNH) from 2005 to 2011.

\section{METHODS}

This analysis was based on data from the Muhimbili National Hospital (MNH) obstetrics database.This electronic database was established in 1998 and currently there are more than 150,000 entries extracted from antenatal cards, midwifery registers, admission books, case notes and maternal death review reports for all deliveries. Analysis for the current study was limited to data that were entered from $1^{\text {st }}$ January 2005 to $31^{\text {st }}$ December, 2011. All the women who carried single tone pregnancies during the study period (and implicitly their babies) were enrolled. Exclusion was made for variables with missing maternal age or year of delivery. All the enrolled women were categorized into three groups according to the mother's age at delivery. These groups were $12-17$ years (teenage), 18 - 34 years (low risk) and $35-50$ years. The two extreme age groups were assumed high risk for obstetric complications and were compared with the 18 - 34 years group as a reference.

During analysis variables with more than $5 \%$ missing information were excluded. The presence of a diagnosis of any one among anemia, hypertension, placenta praevia, malpresentations, malaria, previous Cesarean section, Premature Rupture of Membranes (PROM), Sickle Cell Disease (SCD), Diabetes Mellitus and HIV infection was integrated into a composite variable called any prenatal complication because these conditions are affected by pregnancy and are commonly mentioned in literature as adverse prenatal conditions in association with maternal age. For each of the extreme age groups the annual incidence of delivery was calculated as number per 1000 deliveries in the same year and trends over the study years were described. Chi square test and t-test were used to compare proportions and continuous data among two groups respectively. In order to compare the differences in means across the three age groups, one way Analysis of Variance (ANOVA) with Bonferroni adjustment was used. Binary logistic regression analyses were performed with the presence of any prenatal complication (yes/no) as the primary outcome and age as an independent (categorical) variable. Secondary outcome variables had a focus on antenatal care attendance and intra/postnatal events including delivery by Cesarean section, APGAR score at five minutes, stillbirth deliveries, birth weight less than $2.5 \mathrm{~kg}$, birth weight equal or above $4.0 \mathrm{~kg}$ and occurrence of maternal death. For each of the outcome variable crude and adjusted odds ratios and $95 \%$ confidence intervals were established with the low risk age group (18 - 34 years) as a reference. In all the statistics P-values less than 0.05 were interpreted as significant.

Ethical clearance was offered by the Muhimbili University of Health and Allied Sciences (MUHAS) research and publications committee and the permission to conduct the study was granted by MNH authorities.

\section{RESULTS}

A total of 65,453 singleton pregnancies were delivered at MNH from January $1^{\text {st }} 2005$ to December $31^{\text {st }} 2011$. The number eligible for current analysis was $64818(99 \%)$ out of all singleton deliveries. Their ages ranged 12 to 50 years, median of 27.0 years. Among all the eligible deliveries, $9641(14.9 \%)$ were in the two extreme age groups such that $12-17$ years $(\mathrm{n}=1680,2.6 \%)$ and $35-50$ years $(\mathrm{n}=7961,12.3 \%)$. The majority of deliveries $(\mathrm{n}=$ $55176,85.1 \%$ ) were by mothers in the $18-34$ years age group.

Of all the deliveries, $28.4 \%$ had at least one prenatal complication diagnosed. Generally the low risk group was better than the general population of all deliveries conducted at $\mathrm{MNH}$ in terms of its more antenatal visits, lower mean parity and lower rate of maternal deaths (Table 1).

Figure 1 demonstrates trends of annual incidences of deliveries for the two extremes of maternal age (given as annual incidence per 1000 deliveries). There was a progressive increase in the incidence of deliveries by the 35 - 50 years group from 103 in 2005 to 145 per 1000 de- 
Table 1. Comparisons of key variables between the low risk age group and all singleton deliveries at $\mathrm{MNH}$.

\begin{tabular}{|c|c|c|c|}
\hline Outcome Variables & $\begin{array}{l}\text { All singleton } \\
\text { Deliveries } \%{ }^{\mathrm{a}}\end{array}$ & $\begin{array}{l}\text { Low risk age } \\
\text { group } \%{ }^{\mathrm{a}}\end{array}$ & P-value \\
\hline $\begin{array}{l}\text { Any prenatal } \\
\text { complication }^{\mathrm{b}}\end{array}$ & 28.4 & 28.1 & 0.8 \\
\hline $\begin{array}{l}\text { Mean Antenatal } \\
\text { Visits }( \pm \mathrm{SD})\end{array}$ & $4.9( \pm 2.3)$ & $4.9( \pm 2.3)$ & 1.0 \\
\hline $\begin{array}{l}\text { Made at least five } \\
\text { antenatal visits }\end{array}$ & 49.0 & 49.2 & 0.02 \\
\hline Mean Parity $( \pm \mathrm{SD})$ & $2.2( \pm 1.4)$ & $2.0( \pm 1.2)$ & $<0.0001$ \\
\hline $\begin{array}{l}\text { Delivery by } \\
\text { C.section }\end{array}$ & 40.0 & 39.3 & 0.8 \\
\hline $\begin{array}{l}\text { APGAR score } 1-6 \\
\text { at five minutes }\end{array}$ & 7.1 & 7.1 & 1.0 \\
\hline $\begin{array}{l}\text { APGAR score }=0 \text { by } \\
\text { five minutes }\end{array}$ & 7.5 & 7.4 & 0.9 \\
\hline $\begin{array}{l}\text { Mean Birth weight } \\
( \pm \text { SD })\end{array}$ & $3.0( \pm 0.6)$ & $3.0( \pm 0.6)$ & 1.0 \\
\hline Maternal deaths & 0.6 & 0.5 & $<0.0001$ \\
\hline
\end{tabular}

${ }^{\mathrm{a}}$ Data presented as percentages unless indicated otherwise; ${ }^{\mathrm{b}}$ Prenatal complication is a composite variable for anemia, hypertension, placenta praevia, malpresentations, malaria, previous Csection, PROM, SCD, HIV infection and diabetes mellitus.

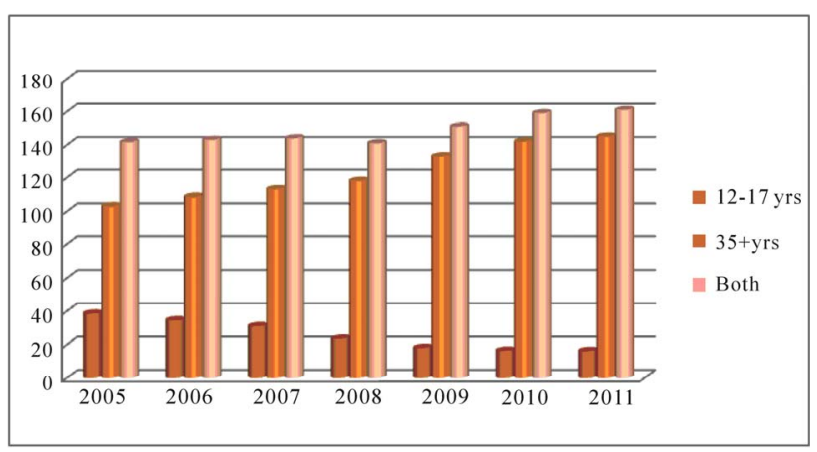

Figure 1. Trends of age specific annual delivery incidence (per 1000 deliveries) at $\mathrm{MNH}$.

liveries in 2011. Deliveries by the teenage group had progressively decline from 39 in 2005 to 16 per 1000 deliveries in 2011. Consequently, the combined annual incidence of deliveries for both extremes of maternal age had increased from 142/1000 in 2005 to $161 / 1000$ deliveries in 2011.

Pregnancy outcomes are compared for the three age groups in Table 2. There was a significant linear trend for the incidence of prenatal complications with the teenage deliveries demonstrating the lowest (11.4\%) and the 35 - 50 years group experiencing the highest $(32.7 \%)$, $\mathrm{Chi}^{2}=51.3, \mathrm{p}<0.0001$. Overall there was a significant difference in mean antenatal visits across the three age groups $(F=253.4, \mathrm{P}<0.0001)$ with teenage deliveries significantly associated with less antenatal visits compared to deliveries at 35 - 50 years (mean difference:
P-value $<0.0001,95 \%$ CI: 1.24 - 1.54). There was a significant difference in mean birth weights across the three compared age groups $(F=82.5, \mathrm{P}<0.0001)$. Teenage compared to deliveries at $35-50$ years had significantly lower mean birth weight (mean difference, $\mathrm{P}<0.0001$, $95 \%$ CI: $0.18-0.27$ ) and higher incidence of low birth weight deliveries $(21.6 \%$ versus $16.3 \%$, P value $<0.0001)$ although across all age groups this latter association was not linear $\left(\mathrm{Chi}^{2}=1.5, \mathrm{p}=0.2\right)$ in Table 2. Likewise, teenage was also associated with low APGAR score deliveries at five minutes $(13.3 \%$ versus $5.1 \%$, P value $<$ 0.0001). Further analysis of the low APGAR score deliveries at five minutes revealed that of all the 4193 deliveries, $42.2 \%$ were delivered by Cesarean Section. The rate of Cesarean section deliveries to such asphyxiated babies was $34.5 \%$ for teenage, $41.8 \%$ for the $18-34$ age group and $49.6 \%$ for deliveries at $35-50$ years. Compared to teenage deliveries, deliveries at $35-50$ years had more proportion of stillbirths $(8.8 \%$ versus $6.8 \%, \mathrm{P}<$ $0.0001)$, more birth weight of $4.0 \mathrm{~kg}$ or above $(6.1 \%$ versus $1.0 \%, \mathrm{P}<0.0001)$ and more Cesarean section rate (46.9\% versus $31.0 \%, \mathrm{P}<0.0001)$.

On a bivariate logistic regression analyses to determine the odds of any prenatal complication, teenage deliveries were comparable or better than the reference age group (18 - 34 years) in all the outcome variables except for the low antenatal attendance of five times or more $(\mathrm{OR}=0.3,95 \% \mathrm{CI}: 0.3-0.4)$, low APGAR score at five minutes $(\mathrm{OR}=2.2,95 \% \mathrm{CI}$ : 1.9 - 2.6) and low birth weight $(\mathrm{OR}=1.6,95 \% \mathrm{CI}$ : $1.4-1.8)$. In contrast, deliveries at maternal age of $35-50$ years had poorer odds in all of the outcome variables except for better antenatal attendance and the marginally lesser incidence of low APGAR score at five minutes (OR $=0.8,95 \%$ CI: 0.7 $0.9)$. Moreover, after adjusting for confounding factors all the odds of poorer outcomes seen on the bivariate analyses for teenage deliveries persisted. For deliveries at maternal age of 35 - 50 years the overall risk for prenatal complication reversed and the better odds for low APGAR score at five minutes previously observed on bivariate analysis were lost. However this group had persistently poorer outcomes for maternal death, delivery of babies $4.0 \mathrm{~kg}$ or above, delivery of low birth weight babies, and delivery by Cesarean section (Table 3).

\section{DISCUSSION}

Methodologically in this study we compared maternal and fetal outcomes of mothers in the extremes of reproductive age based on cutoff ages of 18 and 35 years. According to WHO, UNICEF and UNFPA delaying first pregnancy until at least the age of 18 years is healthy and below this age is risky for obstetric complications [22]. Likewise, an overwhelmingly large number of studies 
Table 2. Comparisons of occurrence of pregnancy outcomes across all maternal age groups.

\begin{tabular}{ccccc}
\hline Pregnancy outcomes & $12-17$ yrs n $(\%)$ & $18-34$ yrs n (\%) & $35-50$ yrs n (\%) & Statistics \\
\hline Any prenatal complication & $191(11.4)$ & $15,204(28.1)$ & $2607(32.7)$ & $\mathrm{Chi}^{2}=51.3, \mathrm{P}<0.0001$ \\
Antenatal visits (mean \pm SD) & $3.6( \pm 1.8)$ & $4.9( \pm 2.3)$ & $5.0( \pm 2.4)$ & $F=253.4, \mathrm{P}<0.0001$ \\
At least five antenatal visits & $419(24.9)$ & $27,172(49.2)$ & $4191(52.7)$ & $\mathrm{Chi}^{2}=213.0, \mathrm{P}<0.0001$ \\
Delivery by C/section & $521(31.0)$ & $21,636(39.3)$ & $3731(46.9)$ & $\mathrm{Chi}^{2}=227.1, \mathrm{P}<0.0001$ \\
APGAR score 1 - 6 at 5 mins & $223(13.3)$ & $3564(7.1)$ & $408(5.1)$ & $\mathrm{Chi}^{2}=85.7, \mathrm{P}<0.0001$ \\
APGAR score $=$ 0 by 5 mins & $115(6.8)$ & $4016(7.4)$ & $700(8.8)$ & $\mathrm{Chi}^{2}=21.4, \mathrm{P}<0.0001$ \\
Birth weight (mean \pm SD) & $2.8( \pm 0.6)$ & $3.0( \pm 0.6)$ & $3.0( \pm 0.7)$ & $F=82.5, \mathrm{P}<0.0001$ \\
Birth weight $<2.5 \mathrm{~kg}$ & $363(21.6)$ & $8396(15.4)$ & $1296(16.3)$ & $\mathrm{Chi}^{2}=1.5, \mathrm{P}=0.2$ \\
Birth weight $\geq 4.0 \mathrm{~kg}$ & $17(1.0)$ & $2207(4.0)$ & $477(6.1)$ & $\mathrm{Chi}^{2}=108.9, \mathrm{P}<0.0001$ \\
Maternal deaths & $9(0.5)$ & $288(0.5)$ & $63(0.8)$ & $\mathrm{Chi}^{2}=7.3, \mathrm{P}=0.007$ \\
\hline
\end{tabular}

Table 3. Bivariate and multivariate logistic regression results to estimate risks for pregnancy outcomes using the 18 - 34 years group as a reference.

\begin{tabular}{ccccc}
\hline \multirow{2}{*}{ Pregnancy outcomes } & \multicolumn{2}{c}{ Age 12 - 17 years } & \multicolumn{2}{c}{ Age 35 - 50 years } \\
\cline { 2 - 5 } & ${ }^{*}$ Crude OR $(95 \% \mathrm{CI})$ & ${ }^{*}$ Adjusted OR $(95 \% \mathrm{CI})$ & ${ }^{*}$ Crude OR $(95 \% \mathrm{CI})$ & ${ }^{*}$ Adjusted OR $(95 \% \mathrm{CI})$ \\
\hline Any prenatal complication ${ }^{\dagger}$ & $0.3(0.3-0.4)$ & $0.4(0.3-0.5)$ & $1.3(1.2-1.4)$ & $0.9(0.8-0.9)$ \\
At least five antenatal visits & $0.3(0.3-0.4)$ & $0.3(0.3-0.4)$ & $1.2(1.1-1.2)$ & $1.3(1.3-1.4)$ \\
Delivery by C. section & $0.7(0.6-0.8)$ & $0.9(0.8-1.0)$ & $1.4(1.3-1.4)$ & $1.4(1.3-1.5)$ \\
APGAR score $1-6(5 \mathrm{~min})$ & $2.2(1.9-2.6)$ & $1.9(1.6-2.2)$ & $0.8(0.7-0.9)$ & $1.0(0.9-1.1)$ \\
APGAR score $=0$ by $5 \mathrm{~min}$ & $0.9(0.8-1.1)$ & $1.0(0.8-1.3)$ & $1.2(1.1-1.3)$ & $1.1(1.0-1.2)$ \\
Birth weight $<2.5 \mathrm{~kg}$ & $1.6(1.4-1.8)$ & $1.3(1.1-1.5)$ & $1.1(1.0-1.2)$ & $1.2(1.1-1.3)$ \\
Birth weight $\geq 4.0 \mathrm{~kg}$ & $0.2(0.15-0.4)$ & $0.3(0.2-0.5)$ & $1.5(1.4-1.7)$ & $1.2(1.08-1.2)$ \\
Maternal deaths & $1.0(0.5-2.0)$ & $1.0(0.5-2.1)$ & $1.5(1.2-2.0)$ & $1.4(1.1-2.0)$ \\
\hline
\end{tabular}

*The reference age group is 18 - 34 years; ${ }^{\dagger}$ The presence of any prenatal complication was adjusted for gestation age and parity. All other outcome variables were adjusted for the presence of any prenatal complication in addition to gestation age and parity.

consider maternal ages of 35 years and above as risky for adverse pregnancy outcomes [5-8,16,23,24] thus justifying our risky age group categorization. Moreover, we observed better pregnancy outcomes among deliveries in the intermediate age group (18 - 34 years) compared with the general population of all deliveries at $\mathrm{MNH}$ which further supports our assumption of the low risk age group and implicitly the assignment of extremes of the reproductive age into high risk age groups.

During the seven year-periods from 2005 we observed a trend of progressive increase in the proportion of women delivering in extremes of reproductive age. This increase was purely contributed by the progressive rise in the proportion of deliveries by women at the age of 35 50 years in the background of a progressive decrease in proportions of teenage deliveries. A similar trend was reported at the same hospital from 1999 [15] indicating that the delivering population at $\mathrm{MNH}$ has progressively continued to become older for more than a decade now. These results, albeit hospital based, somehow reflects fertility trends in the general society in Tanzania whereby according to the National survey data, the age specific fertility rate for teenagers (15 - 19 years) has progressively declined from 138 per 1000 women in 1999 through 132 in 2004-5 to 116 in 2010. Likewise, for the age group 35 - 39 years the fertility has progressively increased from 138 per 1000 women in 1999 through 156 per 1000 in 2004-5 and 161 per 1000 in 2010 [25]. Although MNH is a tertiary hospital, over $80 \%$ of deliveries come directly from home without referrals [15], thus mimicking that of district level hospitals. Such a shift in demographic properties of a population in favor of high risk age groups has been observed elsewhere. In Brazil a similar situation in fertility dynamics and in- 
creasingly delivery at older maternal age above 34 years was observed in one province and had contributed significantly to increased poor pregnancy outcomes such as low birth weight deliveries [26].

In the current study both extremes of maternal age were associated with poorer pregnancy outcomes than the referent age group, with teenage deliveries being relatively safer than deliveries at the age of 35 - 50 years. Older women not only had higher incidence of prenatal complications than teenagers, but also had higher incidences of the most serious events of stillbirths and maternal mortality. For the 35 - 50 years group, the increased risk for prenatal complications relative to the low risk group disappeared after controlling for gestation age and parity, thus partly supporting the connotation that adverse events are mainly explained by women's previous medical and reproductive factors $[9,10]$. In contrast to that connotation, however, we observed that controlling prenatal complications, gestation age and parity was not sufficient to abolish intra and postpartum outcomes.

The most serious pregnancy outcomes for teenage deliveries were low APGAR score at five minutes and low birth weight. Low birth weight has proved difficult to control among teenagers as proven by the high incidence across countries regardless the level of economical development $[13,26,27]$. The importance of low socio-economic status of this age group in the causation of low birth weight has been suggested by some studies $[1,2]$ but not by others $[3,4]$. Adding to this complexity, in the current study we found that the risk of low birth weight was independent of parity, gestation age, and the presence or absence of any prenatal complications. These findings put together suggest a biological cause for low birth weight among teenagers. Currently, the impact of low birth weight on development of children born of teenagers is not well understood. Chiltleborough and colleagues had cautioned against targeting teenager mothers in programs seeking to address issues of impact on child development in a population [28]. More research work is needed to explore the role of biological factors in low birth weight born of teenagers and the developmental impact on children born of such mothers.

Low APGAR score at five minutes is largely determined by perinatal and intrapartum care. Implicitly it would be possible to lower the $13 \%$ incidence of low APGAR score among teenage deliveries if they would draw equal attention from health care providers during labor as was the case for older age groups. To the contrary, while only a third of asphyxiated babies born of teenagers were delivered by Cesarean section, the corresponding proportions were $42 \%$ and $50 \%$ for the reference and older age groups respectively. Cesarean section is highly indicated in the majority of cases diagnosed to have fetal distress in labor and the presence of a large number of deliveries with poor APGAR score at five minutes who were not delivered by operative means can be interpreted as an indication of suboptimal care [29,30]. The observed low Cesarean section rate among asphyxiaated babies born of teenagers in the current study proves a relatively high threshold of intervention that health care workers exhibit when caring teenagers in labor at $\mathrm{MNH}$ and supports the notion that mothers and their newborns are exposed to greater risk of adverse outcomes when prenatal and intrapartum care is not to standard [27].

There are limitations to this study. The retrospective nature has denied the flexibility in obtaining important information that could have enhanced comparability of our results with other international studies. Incomplete socio-demographic information, economic level indicators, education level and details of intrapartum care are some of the important variables that could have added value to the current analysis. Thus, in order to improve validity of our study, it was decided a priori to include outcome variables whose missing data were less than $5 \%$. Although we have noted that the composition of delivering population at $\mathrm{MNH}$ may not differ from that at lower hospitals, being a hospital based study the results are in no way representative of what is happening in the community. However, the fact that $100 \%$ pregnant women in Dar es Salaam attend antenatal clinic and 91\% deliveries are attended by skilled birth attendant usually in health facilities [25], one expects the composition of all deliveries in this study to be closer to that in the general population since over $80 \%$ of deliveries at $\mathrm{MNH}$ are not referred. Moreover, this study did not capture miscarriages at the gestation younger than 28 weeks because such cases are usually not admitted in the maternity wards at $\mathrm{MNH}$ which denied us a complete picture about pregnancy outcomes.

In conclusion, the population of mothers delivering at $\mathrm{MNH}$ has continued to become progressively older in the past decade. Although mothers in both extremes of reproductive age carry a higher risks for adverse pregnancy outcomes compared with those in the 18 - 34 years, older mothers in the ages 35 - 50 years are at more risk for poor pregnancy outcomes than teenage deliveries. National policies should pay more attention to this age group if they have to reduce maternal and perinatal morbidities and mortality.

\section{ACKNOWLEDGEMENTS}

We gratefully acknowledge MNH administration for permission to conduct the study.

\section{REFERENCES}

[1] Ayuba, I.I. and Gani, O. (2012) Outcome of teenage 
pregnancy in the niger delta of Nigeria. Ethiopian Journal of Health Sciences, 22, 45-50.

[2] Gibbs, C.M., Wendt, A., Peters, S. and Hogue, C.J. (2012) The impact of early age at first childbirth on maternal and infant health. Paediatric and Perinatal Epidemiology, 26, 259-284. doi:10.1111/j.1365-3016.2012.01290.x

[3] Chen, X.K., Wen, S.W., Fleming, N., Demissie, K., Rhoads, G.G. and Walker, M. (2007) Teenage pregnancy and adverse birth outcomes: A large population based retrospective cohort study. International Journal of Epidemiology, 36, 368-373.

[4] Chen, X.K., Wen, S.W., Fleming, N., Demissie, K., Rhoads, G.G. and Walker, M. (2008) Increased risks of neonatal and postneonatal mortality associated with teenage pregnancy had different explanations. Journal of Clinical Epidemiology, 61, 688-694. doi:10.1016/j.jclinepi.2007.08.009

[5] Kirchengast, S. (2007) Maternal age and pregnancy outcome: An anthropological approach. Anthropologischer Anzeiger, 65, 181-191.

[6] Jahan, M.K., Shafiquzzaman, M., Nahar, K., Rahman, M., Sultana, N., Rahman, M.M., et al. (2009) Outcome of pregnancy in women 35 years of age and above. Mymensingh Medical Journal, 18, 7-12.

[7] Hanif, H.M. (2011) Association between maternal age and pregnancy outcome: Implications for the Pakistani society. Journal of the Pakistan Medical Association, 61, 313-319.

[8] Koo, Y.J., Ryu, H.M., Yang, J.P., Lim, J.H., Lee, J.E., Kim, M.Y., et al. (2012) Pregnancy outcomes according to increasing maternal age. Taiwanese Journal of Obstetrics and Gynecology, 51, 60-65.

[9] Berkowitz, G.S., Skovron, M.L., Lapinski, R.H. and Berkowitz, R.L. (1990) Delayed childbearing and the outcome of pregnancy. The New England Journal of Medicine, 322, 659-664. doi:10.1056/NEJM199003083221004

[10] Taffa, N. (2003) A comparison of pregnancy and child health outcomes between teenage and adult mothers in the slums of Nairobi, Kenya. International Journal of Adolescent Medicine and Health, 15, 321-329. doi:10.1515/IJAMH.2003.15.4.321

[11] Chen, X.K., Wen, S.W., Smith, G., Leader, A., Sutandar, M., Yang, Q., et al. (2006) Maternal age, paternal age and new-onset hypertension in late pregnancy. Hypertens Pregnancy, 25, 217-227.

doi:10.1080/10641950600912992

[12] Watcharaseranee, N., Pinchantra, P. and Piyaman, S. (2006) The incidence and complications of teenage pregnancy at Chonburi Hospital. Journal of the Medical Association of Thailand, 89, S118-S123.

[13] Shrim, A., Ates, S., Mallozzi, A., Brown, R., Ponette, V., Levin, I., et al. (2011) Is young maternal age really a risk factor for adverse pregnancy outcome in a canadian tertiary referral hospital? Journal of Pediatric and Adolescent Gynecology, 24, 218-222.

[14] Goonewardene, I.M. and Deeyagaha-Waduge, R.P. (2005) Adverse effects of teenage pregnancy. Ceylon Medical
Journal, 50, 116-120.

[15] Muganyizi, P.S. and Kidanto, H.L. (2009) Impact of change in maternal age composition on the incidence of Caesarean section and low birth weight: Analysis of delivery records at a tertiary hospital in Tanzania, 1999-2005. BMC Pregnancy Childbirth, 9, 30.

[16] Carolan, M. and Nelson, S. (2007) First mothering over 35 years: Questioning the association of maternal age and pregnancy risk. Health Care for Women International, 28, 534-555.

[17] Yogev, Y., Melamed, N., Bardin, R., Tenenbaum-Gavish, K., Ben-Shitrit, G. and Ben-Haroush, A. (2010) Pregnancy outcome at extremely advanced maternal age. American Journal of Obstetrics \& Gynecology, 203, e551-e557.

[18] Alshami, H.A., Kadasne, A.R., Khalfan, M., Iqbal, S.Z. and Mirghani, H.M. (2011) Pregnancy outcome in late maternal age in a high-income developing country. Archives of Gynecology and Obstetrics, 284, 1113-1116. doi:10.1007/s00404-010-1821-6

[19] Kathiresan, A.S., Roca, L.E., Istwan, N., Desch, C., Cordova, Y.C., Tudela, F.J., et al. (2011) The influence of maternal age on pregnancy outcome in nulliparous women with twin gestation. American Journal of Perinatology, 28, 355-360. doi:10.1055/s-0030-1270117

[20] Galvez, M. and Myles, T.D. (2005) Teenage pregnancy in the Texas Panhandle. The Journal of Rural Health, 21, 259-262. doi:10.1111/j.1748-0361.2005.tb00092.x

[21] Norton, M. and Shelton, J.D. (2011) Stillbirth and healthy timing and spacing of pregnancy. Lancet, 378, 876-877.

[22] Lane, C., Joof, Y.M., Hassan, A.A. and Pryor, S. (2012) Promoting healthy timing and spacing of pregnancy with young married women in Northern Nigeria: A short report. African Journal of Reproductive Health, 16, 263269.

[23] Lampinen, R., Vehvilainen-Julkunen, K. and Kankkunen, P. (2009) A review of pregnancy in women over 35 years of age. Open Journal of Nursing, 3, 33-38. doi: $10.2174 / 1874434600903010033$

[24] Ludford, I., Scheil, W., Tucker, G. and Grivell, R. (2012) Pregnancy outcomes for nulliparous women of advanced maternal age in South Australia, 1998-2008. Australian and New Zealand Journal of Obstetrics and Gynaecology, 52, 235-241. doi:10.1111/j.1479-828X.2012.01442.x

[25] National Bureau of Statistics (NBS) [Tanzania] and ICF Macro (2011) Tanzania demographic and health survey 2010. NBS and ICF Macro, Dar es Salaam.

[26] da Silva, C.H., Hernandez, A.R., Agranonik, M. and Goldani, M.Z. (2012) Maternal age and low birth weight: A reinterpretation of their association under a demographic transition in Southern Brazil. Maternal and Child Health Journal, in press. doi:10.1007/s10995-012-1030-y

[27] Vieira, C.L., Coeli, C.M., Pinheiro, R.S., Brandao, E.R., Camargo Jr., K.R., and Aguiar, F.P. (2012) Modifying effect of prenatal care on the association between young maternal age and adverse birth outcomes. Journal of Pediatric and Adolescent Gynecology, 25, 185-189.

[28] Chittleborough, C.R., Lawlor, D.A. and Lynch, J.W. (2011) Young maternal age and poor child development: 
Predictive validity from a birth cohort. Pediatrics, 127, e1436-e1444.

[29] Bahiah, A.S., Murphy, J.F. and Sharida, H.E. (2010) Fetal distress in labor and caesarian section rate. Bahrain Medical Bulletin, 32.

http://www.bahrainmedicalbulletin.com/june_2010/fetal-
distress-Mod.pdf

[30] Kumari, R., Srichand, P., Devrajani, B.R., Shah, S.Z., Devrajani, T., Bibi, I. and Kumar, R. (2012) Foetal outcome in patients with meconium stained liquor. Journal of the Pakistan Medical Association, 62, 474-476. 